\title{
CLIMATE VARIABILITY STUDIES WITH A PRIMITIVE EQUATION MODEL OF THE EQUATORIAL PACIFIC
}

\author{
M. LATIF, E. MAIER-REIMER and D.J. OLBERS
}

ABSTRACT

A primitive equation equatorial model has been developed to study climate variability due to wind and thermodynamic forcing in an equatorial region. The model basin extends from $30^{\circ} \mathrm{S}$ to $30^{\circ} \mathrm{N}$ and zonally over $140^{\circ}$, has a variable horizontal resolution $(50-800 \mathrm{~km})$ and 13 vertical levels. Experiments are performed with observed annual cycle as well as 32 years of observed bimonthly wind data. A preliminary analysis of these experiments shows that the model is capable of simulating the basic pattern of annual as well as interannual variability of the Pacific Ocean. In particular, the model response shows evidence of the major El Niños which occurred between 1947 and 1978.

\section{INTRODUCTION}

The equatorial Pacific Ocean exhibits the most prominent interannual signal of climate variability known as El Niño. During these events warm surface waters appear for several months over the entire equatorial zone. The relation of the phenomenon to the wind anomaly field has clearly been revealed (Wyrtki, 1975) but also the imbedding of the El Niños in global interannual climate variations has been demonstrated by the connections to the Southern Oscillation (e.g., Wright, 1977) and to teleconnections to North American weather indices (e.g., Horel and Wallace, 1981). Apparently, modelling the Pacific Ocean circulation is an essential prerequisite of understanding and eventually predicting this part of global climate variability. A major step in this task was the clear attribution of observed sealevel variations to equatorially trapped waves forced by realistic wind anomalies (e.g., Busalacchi and O'Brien, 1981; Cane, 1984), a piece of work which was the logical consequence of a series of equatorial wave process studies as those of Hurlburt et al. (1976), McCreary (1976) and Cane (1979a, b). However, these models do not include thermodynamic processes and these are necessary ingredients to predict sea-surface temperature which is the essential parameter in air-sea interaction studies. There is a range of models designed for this purpose where high-resolution, general circulation models represent the highest degree of complexity. In this paper we present an investigation of the response of such a model to realistic wind forcing.

High-resolution oceanic circulation models (OGCM) have traditionally been used to study the mean steady state of the ocean circulation. In the equatorial region, however, the wind forcing is highly variable on time scales comparable with the intrinsic oceanic time scales so that the oceanic adjustment cycles to changing winds appear as relevant to study as the asymptotic mean state of the circulation. Philander has investigated the response of an equatorial OGCM to abruptly and periodically changing winds in a series of 
papers (Philander and Pacanowski, 1980, 1981; Philander, 1981) and has revealed the importance of nonlinear advective effects in addition to the wave processes for the response of the upper ocean. Simulations of the seasonal cycle of the tropical Atlantic Ocean as well as the 1982/83 El Niño event have been performed (S.G.H. Philander, pers. commun., 1984) and have clearly demonstrated the ability of OGCM's to reproduce the observed variations of the thermal and velocity structure of the equatorial ocean in response to the actual wind forcing.

The numerical model used in the present study differs slightly from the model used by Philander. The dimensions of the model are those of the equatorial Pacific. We use variable resolution in the latitudinal and longitudinal directions. In particular in the central Pacific the resolution is considerably coarser than in Philander's model. There is no horizontal diffusive transport of heat and the remaining friction and diffusion parameters are slightly larger than the values used by Philander.

The wind fields are bimonthly data for 32 years resulting from an objective analysis of Barnett (1983) of the data set of Wyrtki and Meyers (1975a, b). It represents a heavily filtered state of the actual Pacific wind field but it was the only wind field available for the range of three decades. The experiment was performed as a sequence, spinning up the model from rest by mean winds, followed by forcing the model with the seasonal cycle and finally by the 32 years of realistic winds. In this paper we present a preliminary analysis of the resulting data set with respect to the mean state, the seasonal cycle and interannual variability of the model. Also, the simulation of El Niño is discussed.

\section{THE MODEL}

The numerical model used in this study is based on primitive equations in the Boussinesq and hydrostatic approximations on an equatorial $\beta$-plane:

$$
\begin{aligned}
& \boldsymbol{u}_{t}+(\boldsymbol{u} \cdot \boldsymbol{\nabla}) \boldsymbol{u}+\beta y \boldsymbol{k} \times \boldsymbol{u}+\boldsymbol{\nabla} p=A_{h} \nabla^{2} \boldsymbol{u}+\left(A_{v} \boldsymbol{u}_{z}\right)_{z} \\
& \boldsymbol{\nabla} \cdot \boldsymbol{u}=0 \\
& T_{\boldsymbol{t}}+(\boldsymbol{u} \cdot \boldsymbol{\nabla}) T=\left(K_{v} T_{z}\right)_{z}
\end{aligned}
$$

There is no horizontal diffusion of heat in the model because there is no physical or numerical reason to incorporate any horizontal mixing. Moreover, the values of diffusion coefficients are notoriously uncertain anyhow.

The pressure is given by:

$p=g \xi-g \alpha \int_{z}^{0} T \mathrm{~d} z^{\prime}$

where $\zeta$ is the surface elevation which is not eliminated as in the GFDL-type models (e.g., Bryan, 1969; Philander and Pacanowski, 1980) but kept as a prognostic variable calculated from the vertically integrated continuity equation:

$\zeta_{t}+\boldsymbol{\nabla} \cdot \int_{-H}^{0} u \mathrm{~d} z=0$ 
This equation is numerically integrated by an implicit algorithm which damps the surface mode but is neutral with respect to the geostrophic mode. The baroclinic part (2.1) and (2.3) is integrated explicitly with a time step of two hours.

The model ocean is a rectangular box with the zonal extent of the Pacific $(14,400 \mathrm{~km})$ and a latitudinal extent of $6600 \mathrm{~km}$ and a constant depth of $4000 \mathrm{~m}$. An Arakawa E-grid is used with variable grid distance: the meridional resolution decreases from $50 \mathrm{~km}$ at the equator to $420 \mathrm{~km}$ at the northern and southern boundaries, the longitudinal resolution is $50 \mathrm{~km}$ at the coasts and decreases to $800 \mathrm{~km}$ in the center. The 13 vertical levels are spaced $10 \mathrm{~m}$ near the surface and the spacing increases to $500 \mathrm{~m}$ below $500 \mathrm{~m}$ depth. The vertical velocity is computed between the levels. The eddy viscosities $A_{v}$ and $A_{h}$ and the diffusivity $K_{v}$ are chosen constant with values $A_{v}=15, A_{h}=10^{8}$ and $K_{v}=1$ in units $\mathrm{cm}^{2} \mathrm{~s}^{-1}$

The model is forced at the surface by wind and heating:

$A_{v} u_{z}=t_{-0} \quad$ at $z=0$

$K_{v} T_{z}=\gamma\left(T_{0}-T\right)$

where the wind stress $t_{-0}$ and the forcing temperature $T_{0}$ are prescribed. The wind stress field is described in Section 3, the forcing temperature was taken constant as $T_{0}=26^{\circ} \mathrm{C}$. The constant $\gamma$ determines the time scale on which the surface temperature would relax to $T_{0}$ in the absence of advection (Haney, 1971). With the thickness $d=10 \mathrm{~m}$ of our first layer this time scale $d / \gamma$ is chosen as 28 days.

At the bottom (which is flat) and at lateral boundaries a no-slip condition is used. We apply a no-heat flux condition at the bottom. Since there is no explicit horizontal diffusion of temperature, no further boundary conditions are needed. Notice, however, that with these boundary conditions the model ocean is thermally isolated at the walls and the bottom. So starting with an initial temperature field $T<T_{0}$, the ocean will continually become warmer due to the surface heat flux (2.7).

\section{THE WIND FIELD}

The wind field was taken from an objective analysis of the Wyrtki and Meyers (1975a, b) data set by Barnett (1983). This analysis yielded bimonthly wind vectors for the period $1947-1978$ in the equatorial strip $30^{\circ} \mathrm{S}-30^{\circ} \mathrm{N}$ and $150^{\circ} \mathrm{E}-80^{\circ} \mathrm{W}$. The annual cycle of this data set is given on a $2^{\circ} \times 10^{\circ}$ grid, wind anomalies have been smoothed on a $4^{\circ} \times 20^{\circ}$ grid. Barnett's analysis used a filtering technique based on empirical orthogonal functions which eliminated small-scale noise. Figure 1 shows an example of wind anomalies before and after filtering for the particular bimonth. As pointed out by Barnett from a statistical point of view, only ten EOF's (which make about half of the observed variance) of the anomaly field can be classified as signal. The first five EOF's have been included in the analysed wind field. These describe about $45 \%$ of the variance. Apparently, the filtering is rather strong and the variability in the model can be expected to be too weak. However, though being not optimal for an equatorial variability study the wind field was the only one available to us, covering this extended range of three decades.

The wind vectors were interpolated onto the model grid and wind stress vectors were 

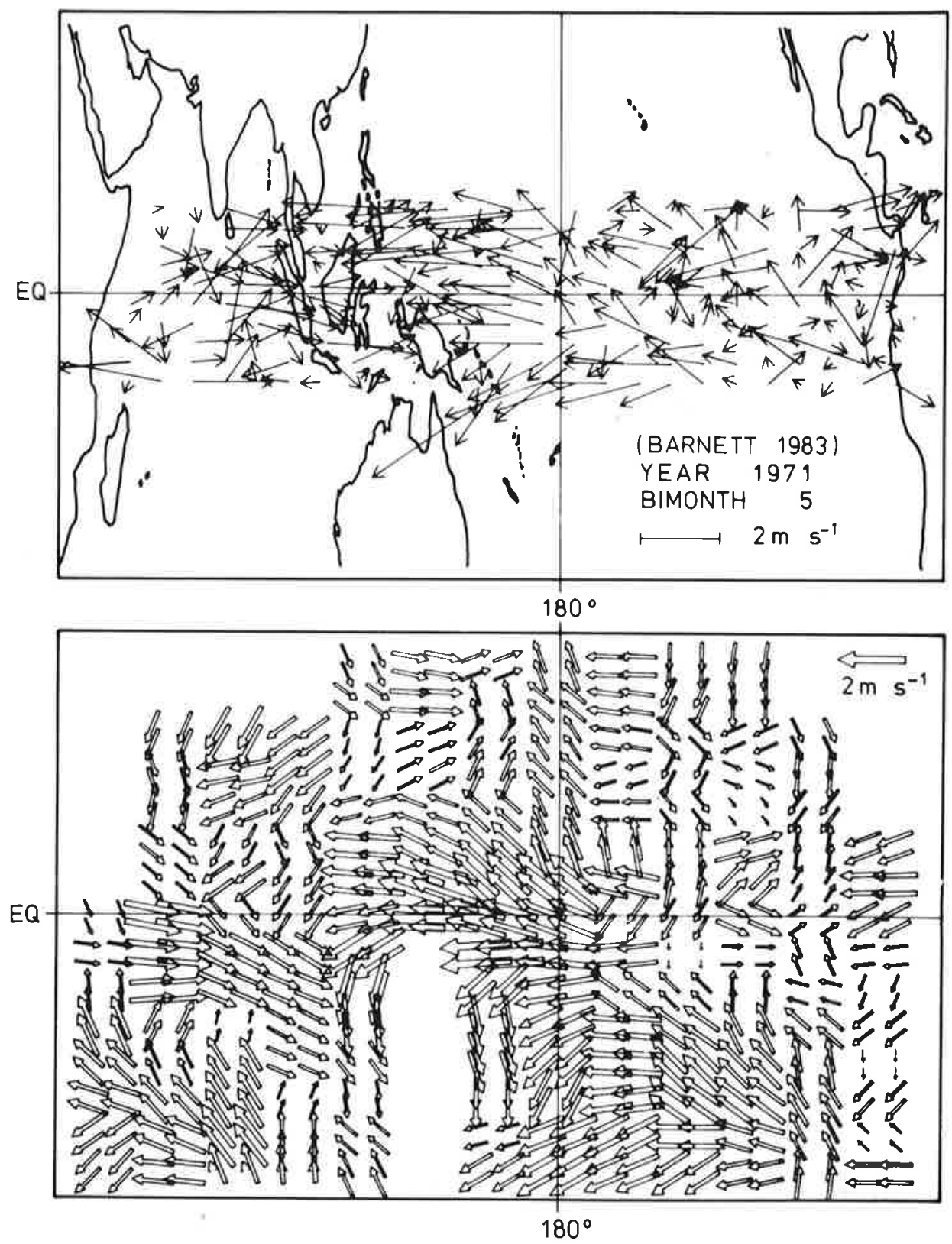

Fig. 1. Original wind anomalies (upper panel, from Barnett (1983)) and reconstructed anomaly field (lower panel) for bimonth 5 of 1971.

calculated with a constant drag coefficient of $1.5 \times 10^{-3}$ and interpolated linearly in space and time. For the equatorial wave guide the zonal wind stress component is the most important forcing mechanism and essential in understanding the thermal response. 

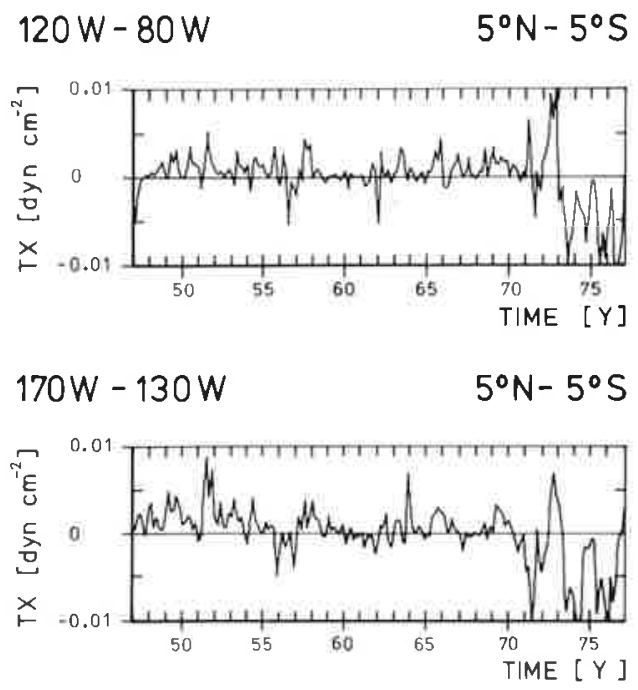

$150 E-180$

$5^{\circ} \mathrm{N}-5^{\circ} \mathrm{S}$

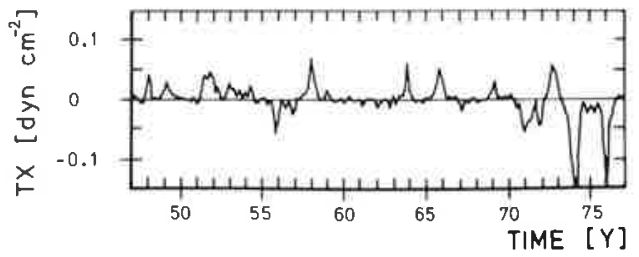

Fig. 2. Time series of zonal wind anomaly averaged over the indicated areas.

Figure 2 displays time series of the anomaly of the zonal wind stress, averaged over three different regions $5^{\circ} \mathrm{S}-5^{\circ} \mathrm{N}$ in the eastern, central and western Pacific. Most obvious is the predominance of westerly anomalies over the entire Pacific after the El Niño year 1972. Notice further that the variance in the eastern and central Pacific is much less than in the western Pacific.

\section{THE EXPERIMENTS}

The sequence of experiments is displayed schematically in Fig. 3a. Initially the ocean was at rest with a horizontally uniform stratification displayed in Fig. 3b. At $t=0$ the mean annual wind was switched on. These mean winds were obtained by averaging the climatological seasonal cycle of Barnett's (1983) data. After seven months of integration the system was close to a steady state. Integration was then carried on using the seasonal cycle of the wind field. After three cycles the model reached an almost cyclostationary state. Then the wind anomalies for the period 1947-1978 were imposed upon the seasonal cycle in order to stimulate the interannual variability of the Pacific Ocean over these 32 years. 
(a) forcing :

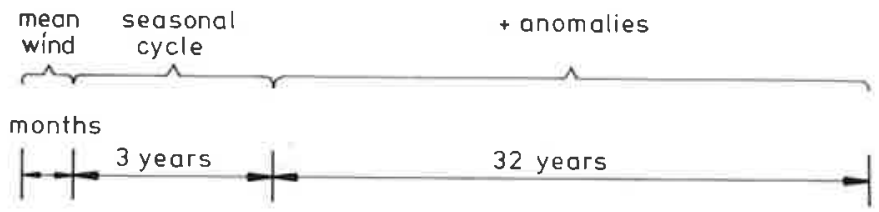

spin up

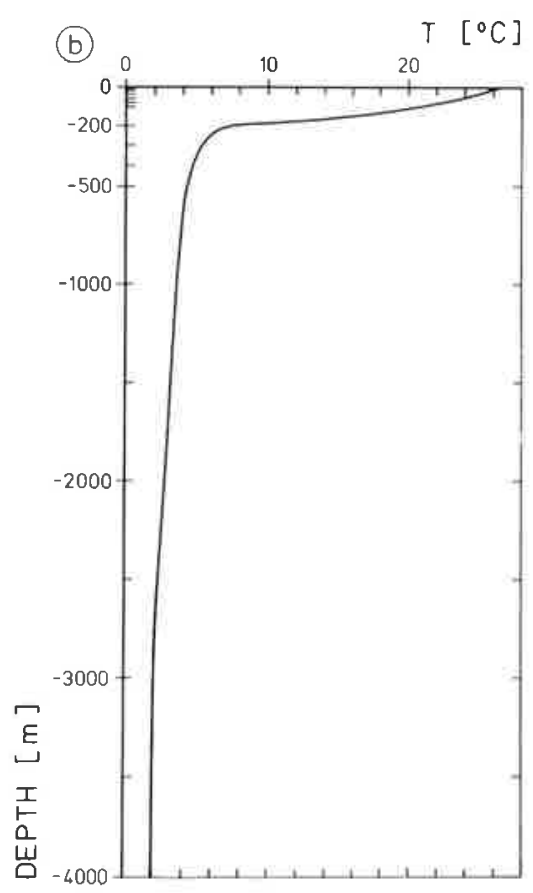

Fig. 3. (a) Sequence of experiments; (b) temperature profile at the start of the spin-up phase.

Results will be presented for the situations after the spin-up experiment, for the seasonal cycle, and during the 32-year run.

\subsection{The spin-up experiment}

After the seven months of the spin-up phase the model was not in complete equilibrium but the major features of the equatorial currents and the temperature field were clearly established. A meridional section of the zonal velocity and the temperature field in the upper $300 \mathrm{~m}$ is shown in Fig. 4a. There is a westward surface current with velocities up to $30 \mathrm{~cm} \mathrm{~s}^{-1}$, on top of an eastward undercurrent with a speed of about $50 \mathrm{~cm} \mathrm{~s}^{-1}$ in its core at about $100 \mathrm{~m}$ depth. The width of the undercurrent, about $3^{\circ}$, is controlled both by horizontal friction and by inertial effects since the scales $\left(A_{h} / \beta\right)^{1 / 3} \cong 125 \mathrm{~km}$ and also $(U / \beta)^{1 / 2} \cong 100 \mathrm{~km}$ have comparable magnitude. At about $8^{\circ} \mathrm{N}$ the equatorial counter 
(a)

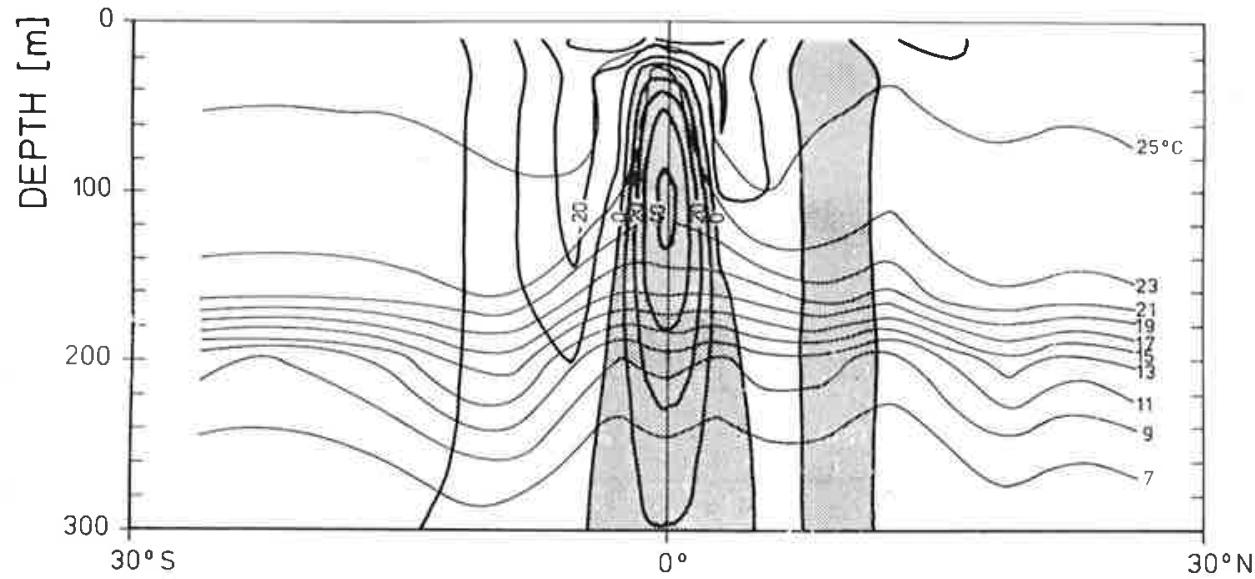

LATITUDE

(b)

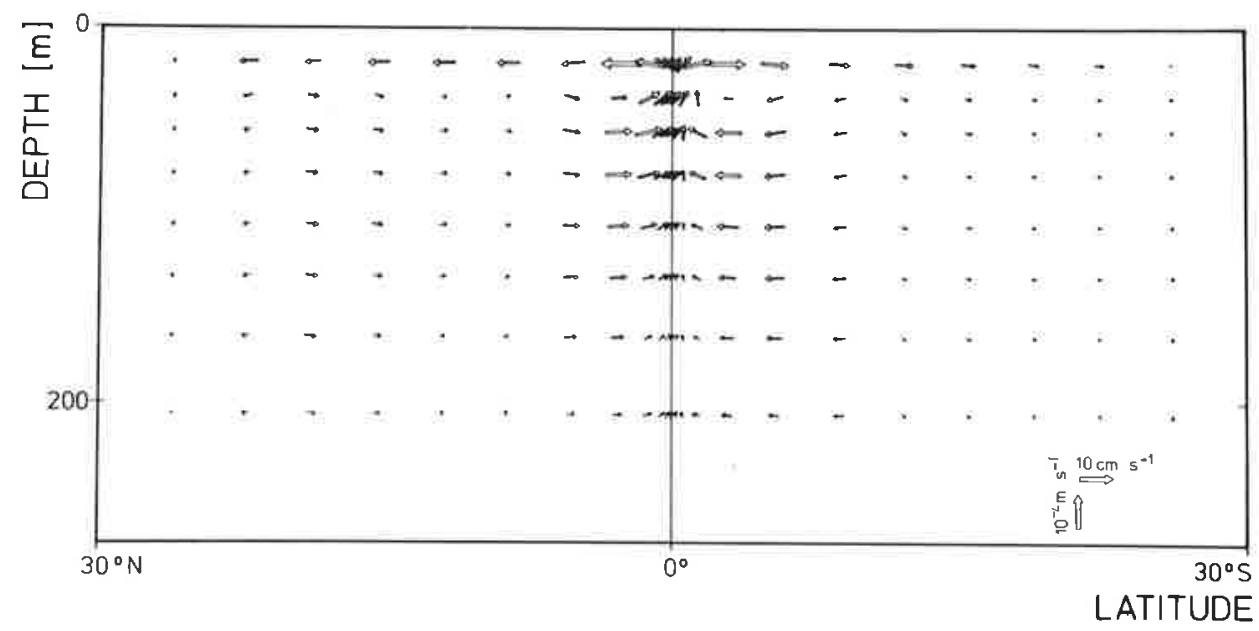

Fig. 4. (a) Meridional cross-section of zonal velocity and of temperature along the central meridian at the end of the spin-up phase; shaded area has eastward velocities; (b) meridional circulation along the central meridian at the end of the spin-up phase.

current appears with velocities up to $10 \mathrm{~cm} \mathrm{~s}^{-1}$. The temperature field reveals the familiar spreading in the equatorial strip, associated with the geostrophic convergence and equatorial upwelling. This meridional circulation for the same section is displayed in Fig. 4b. Vertical velocities get up to $0.5 \times 10^{-2} \mathrm{~cm} \mathrm{~s}^{-1}$ above the core of the undercurrent.

Figure 5 shows the SST at the end of the spin-up. The cold water tongue due to upwelling is clearly present with a pool of $21^{\circ} \mathrm{C}$ water located around $120^{\circ} \mathrm{W}$ and an increase to about $26^{\circ} \mathrm{C}$ at the western boundary. This zonal gradient is too weak: in the 


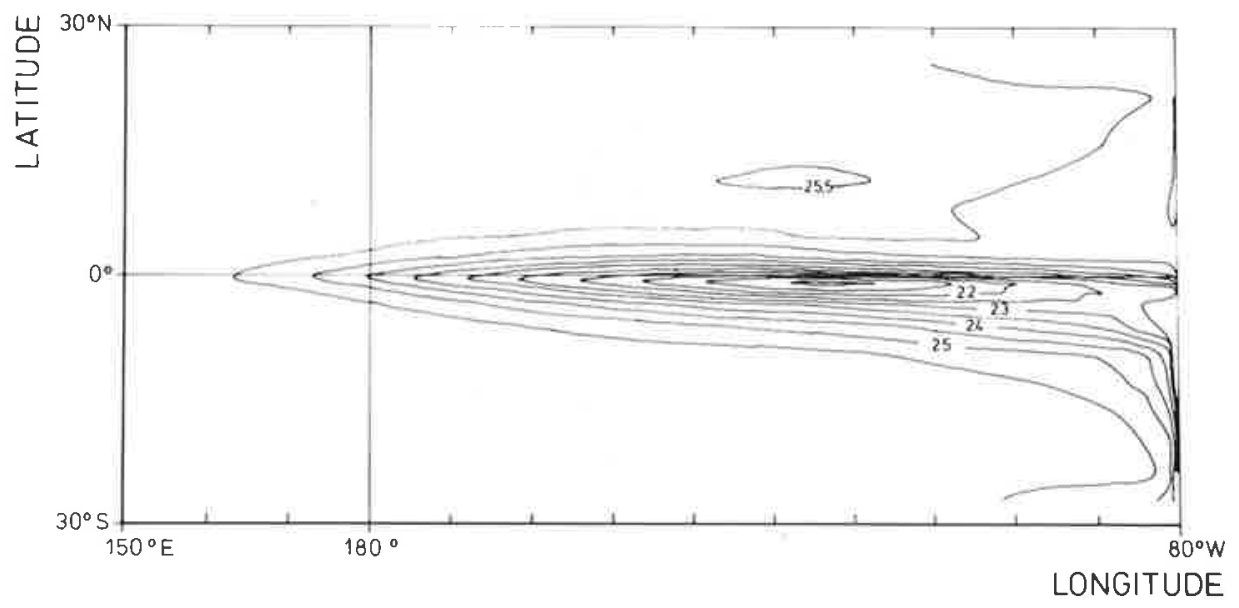

Fig. 5. Sea-surface temperature at the end of the spin-up phase.

atlas of Robinson (1976) we find a pool of $22^{\circ} \mathrm{C}$ water at $95^{\circ} \mathrm{W}$ and about $29^{\circ} \mathrm{C}$ in the western equatorial Pacific.

\subsection{The seasonal cycle}

After forcing the model three years with the seasonal cycle of the wind stress an almost cyclostationary state was reached, showing no significant changes in the model variables between the second and the third cycle. The data of the seasonal cycle presented in this section were, however, extracted from the following 32 years of integration with the full wind forcing.

In Fig. 6 we compare the resulting seasonal cycle of the temperature at the surface and at $100 \mathrm{~m}$ depth at some points along the equator with the corresponding data of the Robinson (1976) atlas. These figures again demonstrate the failure of the model to simulate the zonal temperature gradient correctly. While the mean temperatures agree quite well at the eastern coast they are about $4^{\circ} \mathrm{C}$ too cool in the western part. However, some features are reproduced by the model quite well as the decrease of the annual range of the SST and the decrease of the vertical temperature gradient from east to west. However, the annual range of SST is too small in the model, the maximum is about $1^{\circ} \mathrm{C}$ in the eastern Pacific as compared to about $3^{\circ} \mathrm{C}$ in the Robinson data. Notice that the model range may be a little underestimated due to the bimonthly averaging.

\subsection{The 32-years experiment}

In the last stage of the experiment the model was forced with the 32 years of the actual wind stress field taken from Barnett's (1983) analysis. Only bimonthly averages of the velocity vector and the temperature at all grid points could be saved on tape. A preliminary analysis of this averaged model response is presented in this section. 

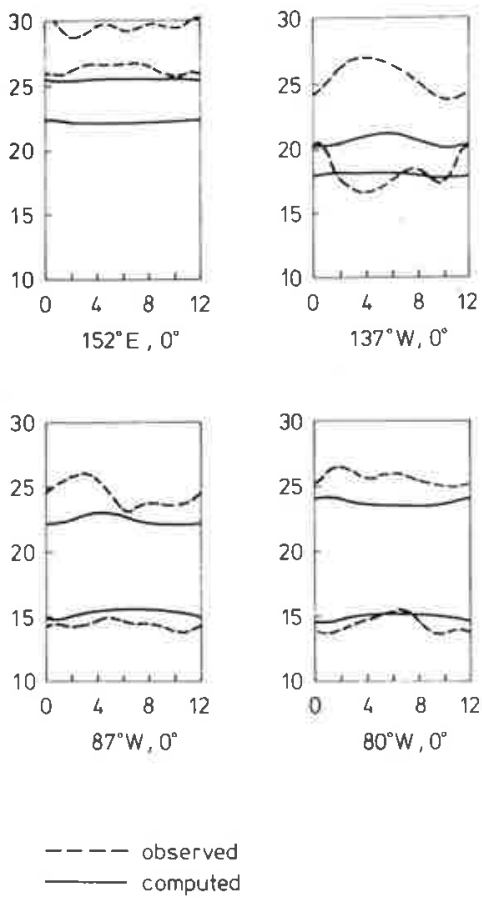

Fig. 6. Seasonal cycle of temperature on the equator at the surface and at $100 \mathrm{~m}$ for different longitudes. Dashed lines represent the observed cycles taken from Robinson (1976).

Figure 7 shows a longitude-time section of the model SST on the equator. The eastern and central response is obviously dominated by the seasonal cycle, most apparent in the cold-water pool centred at about $130^{\circ} \mathrm{W}$. In the western response (emphasized by the $24.0^{\circ} \mathrm{C}$ isotherm) intra- and interannual variations appear to have larger amplitudes than the seasonal cycle. Since model SST anomalies have comparable variances along the equator (as shown below in the center panel of Fig. 8a, b) we can attribute the blurring of seasonal variations in the western part to the low amplitudes of the seasonal cycle discussed in the last section.

A further obvious feature in Fig. 7 is the slow increase of SST in the eastern and central part from the beginning of the experiment until 1971-72. The increase is about $1^{\circ} \mathrm{C}$ over these 25 years, the trend being most obvious in the temperature of the cold water pool and the slow shift of the $22.5^{\circ} \mathrm{C}$ isotherm to the west. The western SST appears not to participate in this trend. An explanation of the warming will be given later.

After 1972 the warming phase abruptly stops and the SST in the eastern part cools by about $1^{\circ}-2^{\circ} \mathrm{C}$. Also, the seasonal amplitude amplifies. This behaviour can be attributed to the sudden occurrence of the large wind stress anomalies over the entire equatorial area east of the date line, which we have pointed out in Fig. 2. Observations of SST do not indicate such a continuous decrease after the El Niño of 1972 . Thus, either the strong 


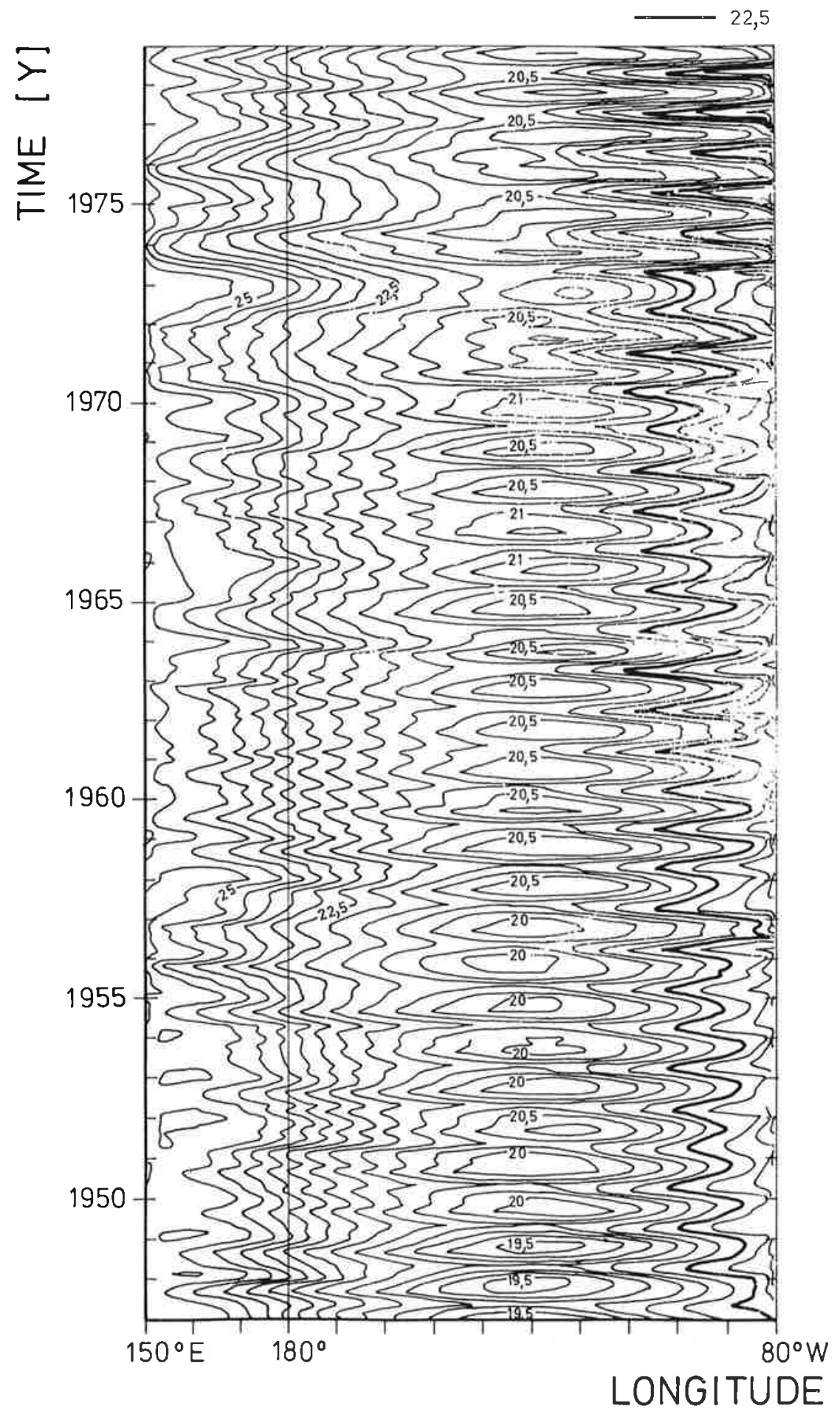

Fig. 7. Longitude-time cross-section of computed sea-surface temperature on the equator from 1947 to 1978 . 
(a)

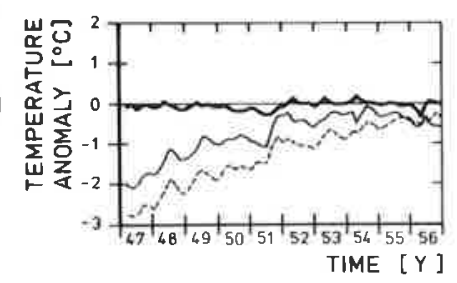

$0^{\circ}$

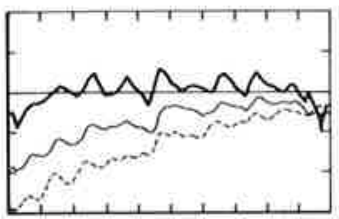

$5^{\circ} \mathrm{S}$

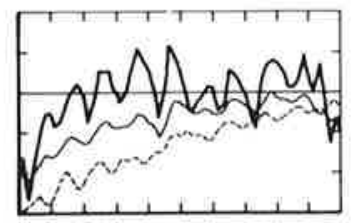

$\longrightarrow \quad 10 \mathrm{~m}$

$--250 \mathrm{~m}$
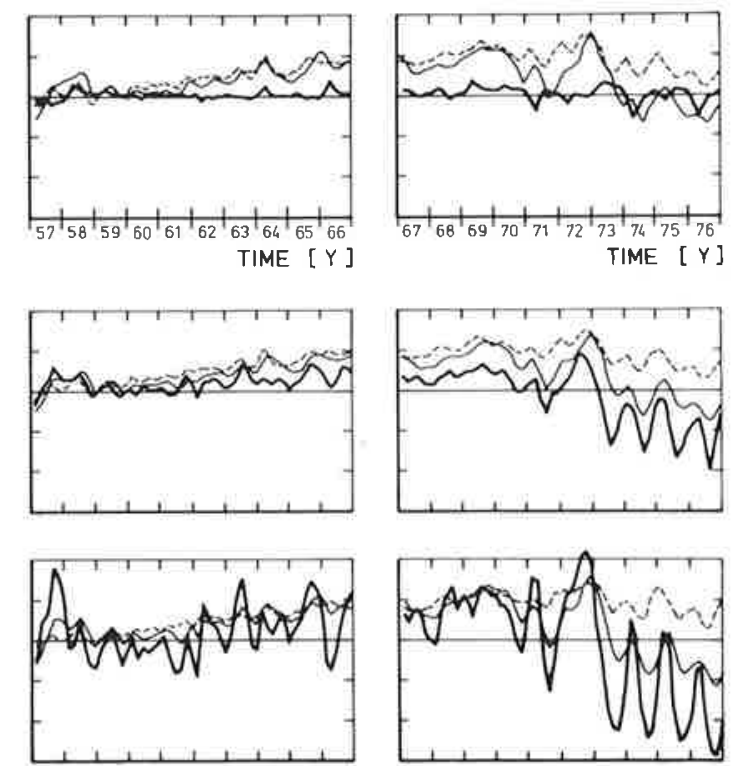

(b)
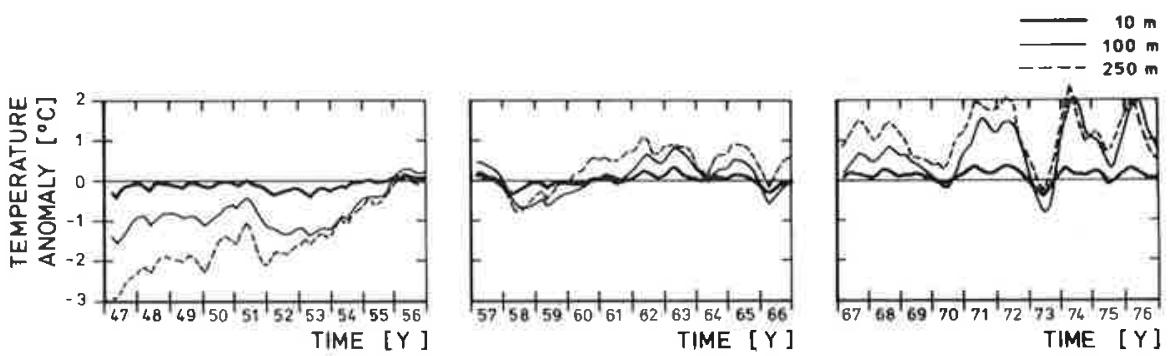

$0^{\circ}$
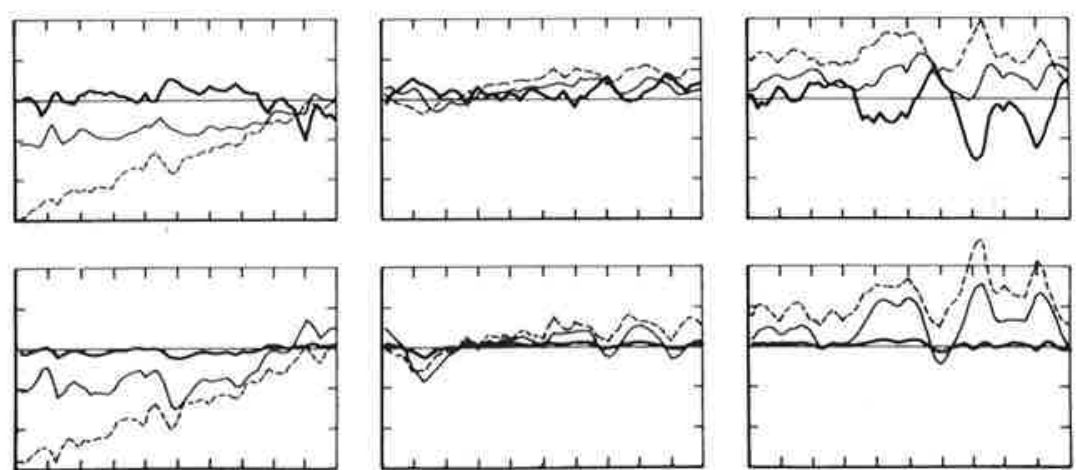

Fig. 8. (a) Time series of temperature anomaly at $80^{\circ} \mathrm{W}$ for 10,100 and $250 \mathrm{~m}$ depth and for $5^{\circ} \mathrm{N}$, $0^{\circ}$ and $5^{\circ} \mathrm{S}$; (b) same as (a), but for $165^{\circ} \mathrm{E}$. 
wind anomaly after 1972 is overemphasized in Barnett's analysis or the sensitivity of the model SST response to wind anomalies is too large. This latter hypothesis, however, is unlikely since the SST variability in the model is too low. This was revealed already in the seasonal amplitudes of Fig. 6 in the last section, but also SST anomalies exemplified
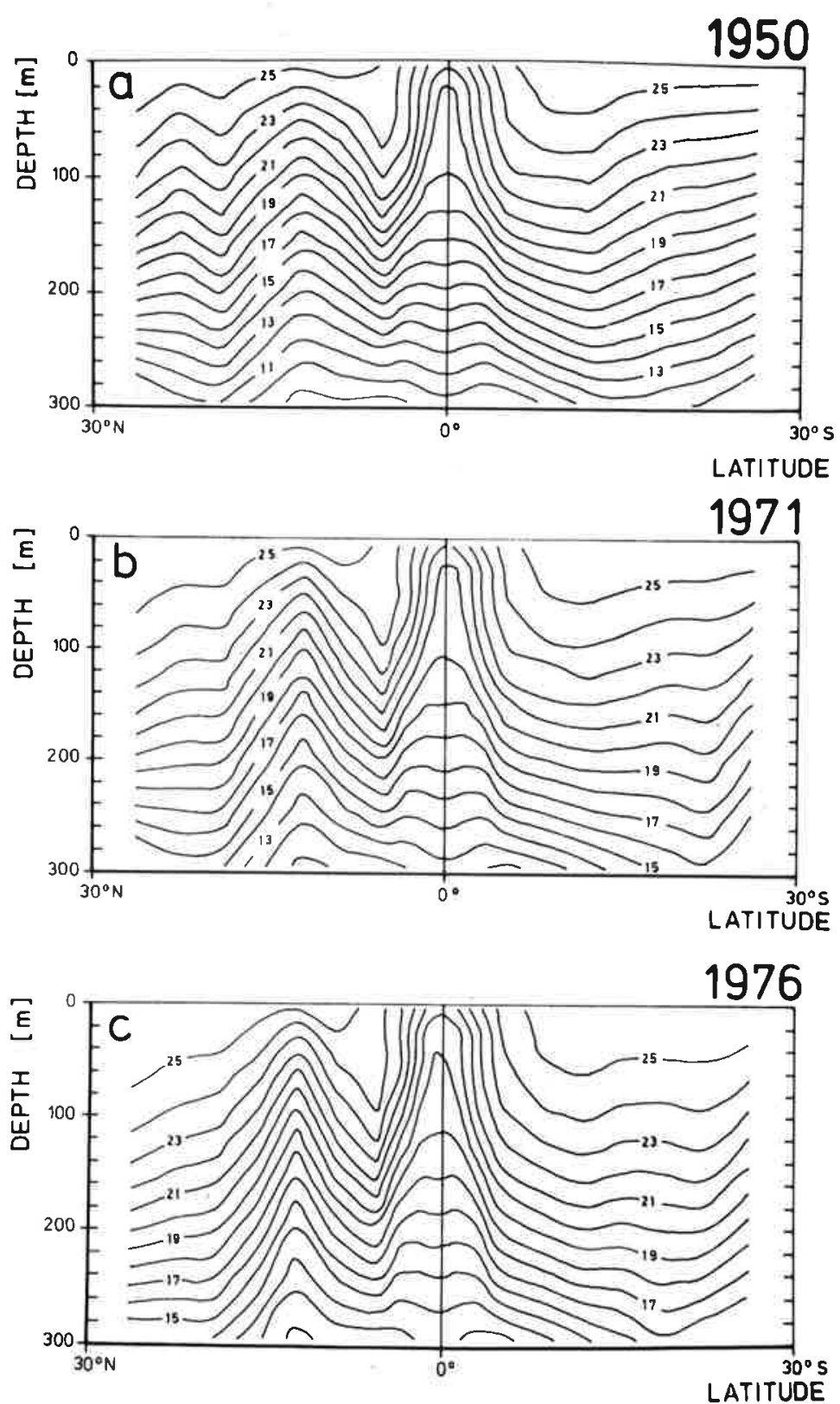

Fig. 9. Meridional cross-section of temperature along the central meridian for (a) Jan./Feb. 1950; (b) Jan./Feb. 1971; and (c) Jan./Feb. 1976. 
in the following figures have too small variances.

Figures $8 \mathrm{a}$ and $\mathrm{b}$ display time series of temperature anomalies at $5^{\circ} \mathrm{N}$, the equator and $5^{\circ} \mathrm{S}$ at the eastern coast $\left(80^{\circ} \mathrm{W}\right)$ and in the western part at $165^{\circ} \mathrm{E}$. Some features of the SST anomaly at the equator (middle panel) have been discussed guided by the full signal in Fig. 7: the slow increase at $80^{\circ} \mathrm{W}$ until 1972 and the drop with an increased annual amplitude thereafter. While the SST anomalies at $5^{\circ} \mathrm{S}, 80^{\circ} \mathrm{W}$ show these features in much pronounced form they are entirely absent at $5^{\circ} \mathrm{N}, 80^{\circ} \mathrm{W}$ and in the western part. Notice also the large regional differences in the SST variances: at $5^{\circ} \mathrm{N}$ and the equator they are small and of comparable magnitude in the eastern and western part, at $5^{\circ} \mathrm{S}$ we find SST anomaly amplitudes of $1^{\circ} \mathrm{C}$ with peak values over $2^{\circ} \mathrm{C}$ in the eastern part and only very low values in the western part.

The behaviour of the temperature anomalies at $100 \mathrm{~m}$ and $250 \mathrm{~m}$ depth is dominated by a much larger warming than the surface temperatures discussed so far. The temperature increases at all locations shown in Fig. 8 by about $2^{\circ} \mathrm{C}$ at $100 \mathrm{~m}$ and about $4^{\circ} \mathrm{C}$ at $250 \mathrm{~m}$. At deeper levels (not shown) the increase diminishes again, the anomaly at $700 \mathrm{~m}$ is an almost straight line with a $1^{\circ} \mathrm{C}$ increase over 32 years and at $2000 \mathrm{~m}$ we find less than $0.5^{\circ} \mathrm{C}$ increase. Still, the basic stratification and structure of the velocity field is not destroyed in the course of the integration: Fig. 9 shows meridional sections of temperature in the center of the basin shortly after the beginning and at the end of the experiment.

The warming of the model can clearly be attributed to the continuous input of heat at the surface. The total input

$Q=\rho c_{p} \gamma \quad \int_{\text {surface }} d^{2} x\left(T_{0}-T\right)$

was fairly constant during the 32 years integration and amounts to $1.25 \times 10^{15} \mathrm{~W}$, about the amount that should leave the equatorial Pacific by meridional transport (e.g., Stommel, 1980). If the total heat received during the 32 years is distributed over $1000 \mathrm{~m}$ the temperature increase is about $3.5^{\circ} \mathrm{C}$ in agreement with our results in the deeper layers. The surface temperature itself does not follow this trend because of the relatively rigid boundary constraint implied by the surface heating parameterization (2.7). Vertical advection and surface heat input are of comparable size for the relaxation time of 28 days used in the boundary condition (2.7).

\section{EL NIÑO EVENTS}

The capability of reduced gravity models and models based on several baroclinic modes to simulate El Niño events by using a realistic wind as forcing has been demonstrated quite successfully in the recent years (e.g., Busalacchi and O'Brien, 1981; Busalacchi and Cane, 1984; Cane, 1984). The connection between pycnocline height and sealevel simulated in these models and SST, which is the essential parameter of air-sea interactions, is however not at all simple, as demonstrated by Schopf and Cane (1983). It appears thus a necessary prerequisite of coupled models to test the performance of 

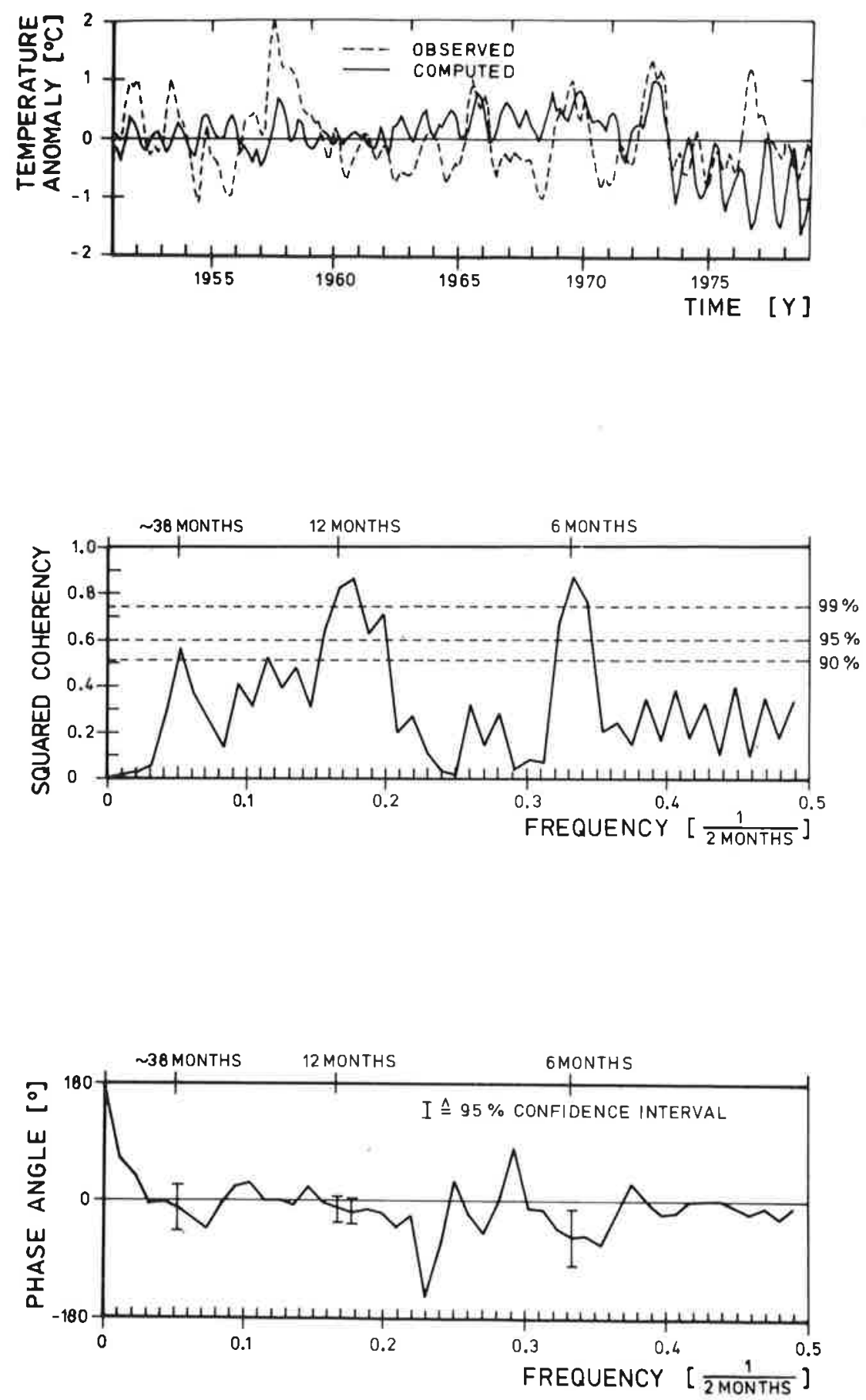

Fig. 10. Time series of computed (full line) and observed (dashed line) sea-surface tempera anomaly at Galapagos (top), coherence spectrum (centre) and phase spectrum (bottom) of the series. 
models which include the thermodynamics. In fact, this was one of the aims of the project.

During the time span 1947-1978 of the 32 years integration there were three major El Niños in the years $1957 / 58,1965$ and 1972. The model was able to simulate the El
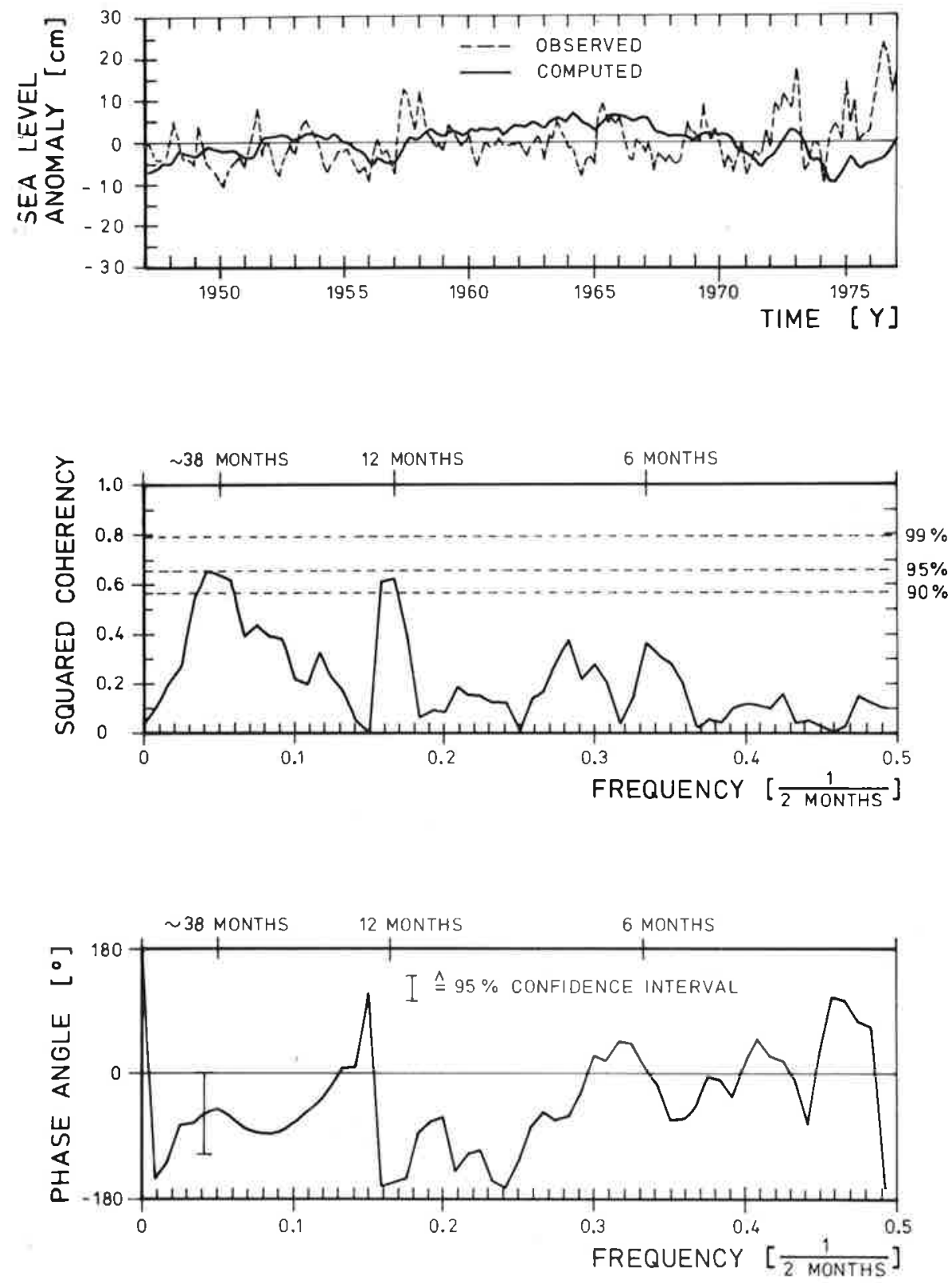

Fig. 11. Same as Fig. 10, but for sealevel anomaly at Talara (Peru). 
Niñ-type pattern in these years, however, as pointed out in the last sections, the SST anomalies in the model have generally too small amplitudes and this defect also applies to the model El Niños.

The occurrence of anomalous warm water at the eastern coast in the years 1957/58 and 1972 is already evident in the time series of temperature anomalies shown in Fig. $8 \mathrm{a}$, particularly on the equator and at $5^{\circ} \mathrm{S}$. A closer comparison of SST anomalies at Galapagos is given in Fig. 10. The simulated anomalies reproduce the warm phases in 1957/58, 1965 and 1972, generally with smaller amplitudes. The colder phases between El Niños do not occur in the model, except for the sudden cooling after 1972. The transition from the cool phase to the $1976 \mathrm{El} \mathrm{Niño,} \mathrm{clearly} \mathrm{visible} \mathrm{in} \mathrm{the} \mathrm{Galapagos} \mathrm{SST} \mathrm{is} \mathrm{not}$ accomplished at all.

Squared coherence and phase of the observed and simulated SST at Galapagos are shown in Figs. 10b and c, computed for the period 1951-1978. Significant peaks (at 99\%) occur at the annual and semiannual period and there is a less significant peak (at 90\%) at a period of about 38 months. The phase vanishes almost consistently over the whole frequency range. Though being only marginally significant the peak at 38 months was found in other cross-spectra for the eastern Pacific. A further example is given in Fig. 11 showing observed and simulated anomalies of sealevel at Talara as well
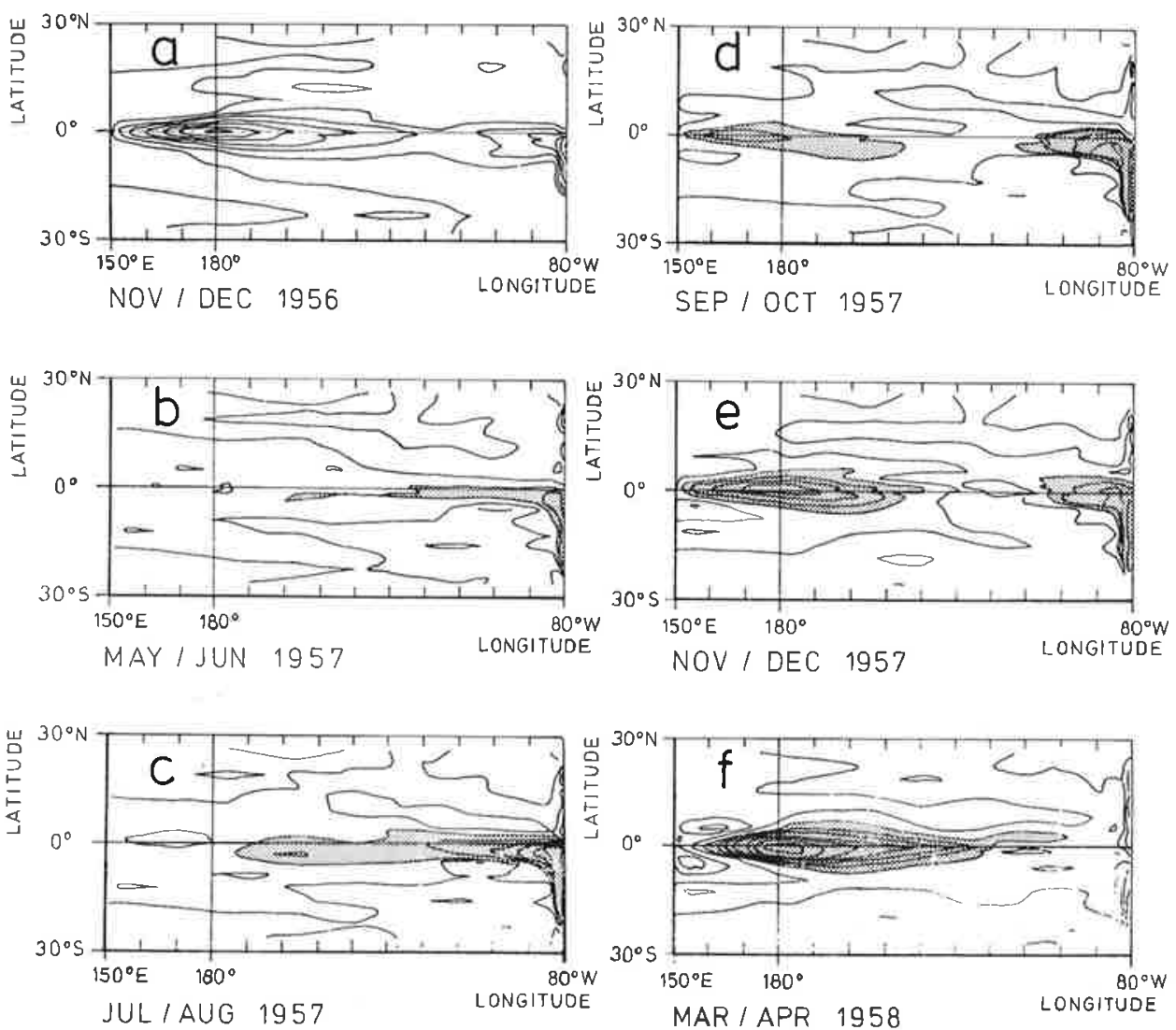

Fig. 12. Evolution of computed sea-surface temperature anomaly during the 1957 El Niño. Shaded areas indicate positive anomalies greater than $0.15^{\circ} \mathrm{C}$. Contour interval is $0.15^{\circ} \mathrm{C}$. 
as their coherence and phase. Rasmusson and Carpenter (1982) have found pronounced peaks in the spectra of the Southern Oscillation index, in the SST at the eastern coast and the sealevel pressure in the eastern Pacific at periods between 36.6 and 42.7 months. The wind field has a peak in this frequency range and apparently the wind forces the model consistently to produce the coherence and correct phase with the corresponding signal in the observed SST and sealevel.

The succession of the SST-anomaly pattern for the El Niños 1957/58 and 1972 is presented in Figs. 12 and 13. By and large the development of the pattern is similar to the El Niño phases as e.g. described in the composite of Rasmusson and Carpenter (1982), but some details do not agree. In most cases these discrepancies can be traced back to differences in the wind anomaly field of Barnett's (1983) analysis and Rasmusson and Carpenter's composite. Consider the development of the model 1957/58 El Niño presented in Fig. 12. In November/December 1956 (Fig. 12a) we find a cold anomaly over the whole equatorial Pacific with a cold pool of water off the eastern coast and around the date line. In early 1957 this starts to disappear and in May/June 1957 (Fig. 12b) a positive anomaly has developed at the east coast which extends along the equator into the eastern Pacific and continues to grow and spread westward until July/August
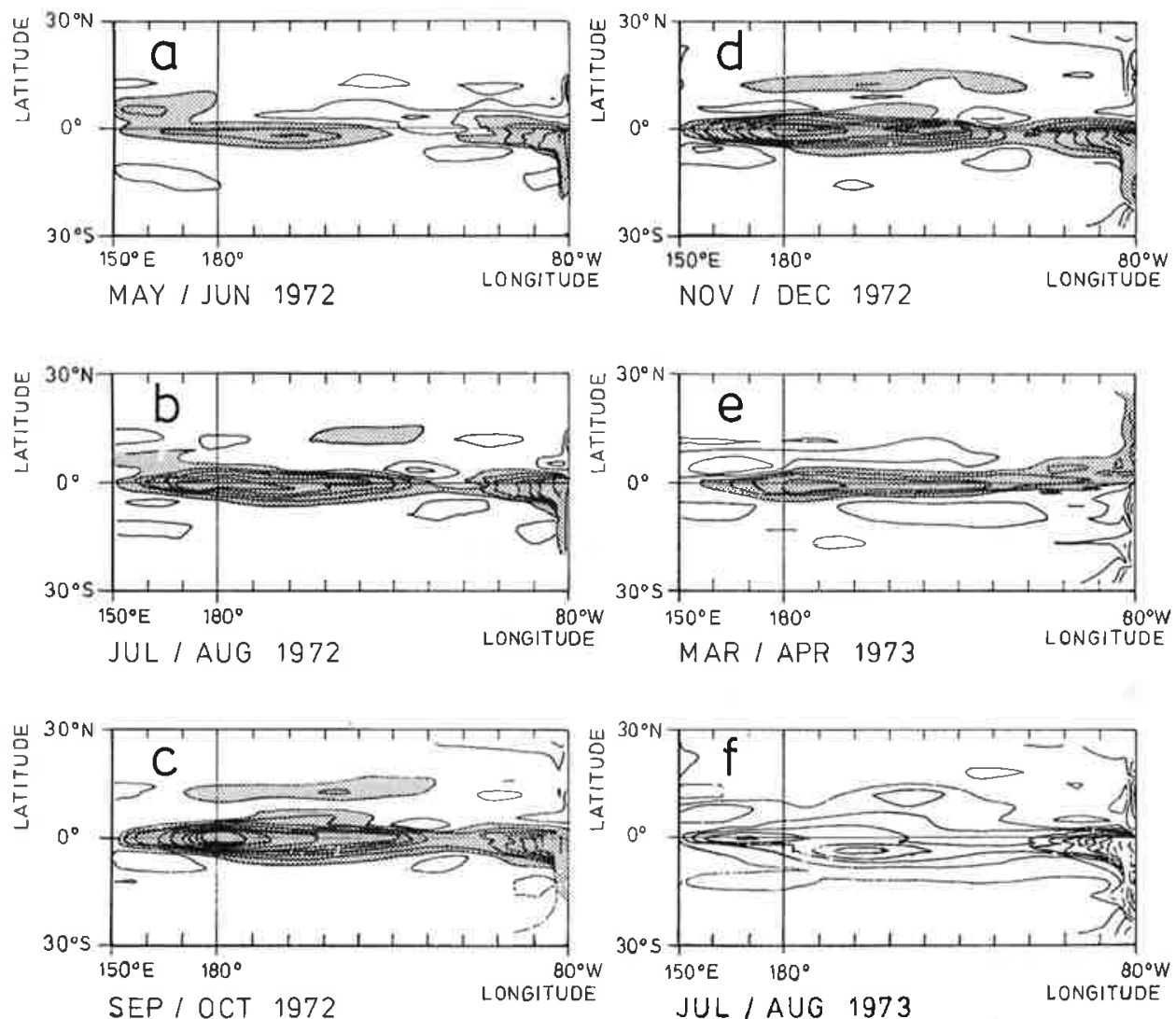

Fig. 13. Same as Fig. 12, but for the 1972 El Niño. 
1957 (Fig. 12c). So far this whole sequence agrees quite well with the composite. In September/October 1957 (Fig. 12d), however, the warm-water tongue starts to separate due to the development of cold anomalies in the central Pacific east of about $140^{\circ} \mathrm{W}$. This entire pattern still grows in amplitude (positive as well as negative anomalies) during November/December 1957 (Fig. 12e). In the following six months the eastern positive anomaly disappears and the western positive anomaly grows and propagates eastward (Fig. 12f) until in the middle of 1958 the whole equatorial region is anomalously warm and the second peak of the 1957/58 E1 Niño develops. The sequence of Fig. 13 shows a similar development for the 1972 El Niño, except that the warm phase in 1972 and early 1973 is followed by basinwide cold anomalies in the middle of 1973.

The splitting of the warm-water tongue during the warming phase is less pronounced in the $1972 \mathrm{El}$ Nin̄o. In both cases this phenomenon can be attributed to strong easter] $]_{\gamma}$ wind anomalies between $120^{\circ}$ and $140^{\circ} \mathrm{W}$ which are not present in Rasmusson and Carpenter's (1982) maps. These wind anomalies converge south of the equator and cause anomalous upwelling of cold water which leads to the splitting of the tongue. We should emphasize that the anomalous wind in this region may be real and that the resulting upwelling only succeeds to produce a cold SST anomaly because the simulated warm anomalies are too small.

\section{DISCUSSION}

The intent of the experiments reported here is to test the climate variability of a highresolution equatorial ocean model forced by realistic winds. Of interest was mainly the response in the thermal structure of the upper ocean, in particular SST, since this is the key oceanic parameter for modelling the coupled ocean-atmosphere system. As briefly outlined in the introduction, the equatorial ocean plays a major role in such a project when dealing with climate variability with time scales up to a decade.

To summarize the results, the model performed reasonably well to reproduce the basic pattern of the thermal and velocity structures of the Pacific Ocean. Amplitudes of the seasonal cycle as well as of interannual variations like the El Niño events are generally too small. However, the overall pattern of these variations are simulated quite well. Besides this realistic variability the model exhibits an artificial warming trend due to continuous heating at the surface and isolated lateral walls at the northern and southern boundaries.

One obvious reason for any disagreement between the model variability and observations is definitely the poor quality of the wind data set. It is clear that the original wind data are severely undersampled, especially in the western Pacific and the southern hemisphere which are the crucial areas for predicting the wave and advective contributions to SST variability. Furthermore, a large part of the variance in the original wind data has been filtered by the objective analysis of Barnett (1983). For this reason work is now in preparation on running the model with other wind data for shorter periods.

\section{ACKNOWLEDGEMENTS}

We appreciate the support of Tim Barnett for making the wind data and SST data available to us. Many thanks also to Klaus Wyrtki for allowing us to use the sealevel data 
We also like to thank Mrs. Marion Grunert for preparing the figures and Mrs. Ulla Kircher for typing the manuscript.

\section{REFERENCES}

Barnett, T.P., 1983. Interaction of the Monsoon and Pacific trade wind system at interannual time scales. Part I: The equatorial zone. Mon. Weather Rev., 111 (4): 756-773.

Bryan, K., 1969. A numerical method for the study of the circulation of the ocean. J. Comp. Phys., 4: $347-376$.

Busalacchi, A.J. and O'Brien, J.J., 1981. Interannual variability of the equatorial Pacific in the 1960's. J. Geophys. Res., 86 (C11): 10901-10907.

Busalacchi, A.J. and Cane, M.A., 1984. Hindcasts of sea level variations during the 1982/1983 E1 Niño. Submitted to J. Phys. Oceanogr.

Cane, M.A., 1979a. The response of an equatorial ocean to simple wind stress patterns: I. Model formulation and analytic results. J. Mar. Res., 37: 232-252.

Cane, M.A., 1979b. The response of an equatorial ocean to simple wind stress patterns: II. Numerical results. J. Mar. Res., 37: 253-299.

Cane, M.A., 1984. Modelling sea level during El Niño. Submitted to J. Phys. Oceanogr.

Haney, R.L., 1971. Surface thermal boundary condition for ocean circulation models. J. Phys. Oceanogr., 1: 241-248.

Horel, J.D. and Wallace, J.M., 1981. Planetary-scale atmospheric phenomena associated with the Southern Oscillation. Mon. Weather Rev., 109: 813-829.

Hurlburt, H.E., Kindle, J.C. and O'Brien, J.J., 1976. A numerical simulation of the onset of E1 Niño. J. Phys. Oceanogr., 5: 621-631.

McCreary, J., 1976. Eastern tropical ocean response to changing wind systems: With application to El Niño. J. Phys. Oceanogr., 6: 632-645.

Philander, S.G.H., 1981. The response of equatorial oceans to a relaxation of the trade wind field. J. Phys. Oceanogr., 11: 176-189.

Philander, S.G.H. and Pacanowski, R.C., 1980. The generation of equatorial currents. J. Geophys. Res., 85: 1123-1136.

Philander, S.G.H. and Pacanowski, R.C., 1981. Response of equatorial oceans to periodic forcing. J. Geophys. Res., 86 (C3): 1903-1916.

Rasmusson, E.N. and Carpenter, T.H., 1982. Variations in tropical sea surface temperature and surface wind fields associated with the Southern Oscillation/El Niño. Mon. Weather Rev., 110: 354384.

Robinson, M.K., 1976. Atlas of North Pacific Ocean, monthly mean temperatures and mean salinities of the surface layer. Naval Oceanographic Office, Ref. Pub1. 2, Washington, D.C.

Schopf, P.S. and Cane, M.A., 1983. On equatorial dynamics, mixed layer physics and sea surface temperature. J. Phys. Oceanogr., 13: 917-935.

Stommel, J., 1980. Asymmetry of interoceanic fresh-water and heat fluxes. Proc. Natl. Acad. Sci., 77: 2377-2381.

Wright, P.B., 1977. The Southern Oscillation-patterns and mechanisms of the teleconnections and the persistence. HIG-77-13, Hawaii Inst. of Geophys., University of Hawaii, Honolulu, Hawaii.

Wyrtki, K., 1975. El Niño - The dynamic response of the equatorial Pacific Ocean to atmospheric forcing. J. Phys. Oceanogr., 5: 572-584.

Wyrtki, K. and Meyers, G., 1975a. The trade wind field over the Pacific Ocean. Part I: The mean field and the annual variation. Rep. HIG-75-1. Hawaii Inst. Geophys., University of Hawaii, Honolulu, Hawaii, $26 \mathrm{pp}$.

Wyrtki, K. and Meyers, G., 1975b. The trade wind field over the Pacific Ocean. Part II: Bimonthly fields of wind stress; 1950 to 1972 . Rep. HIG-75-2. Hawaii Inst. Geophys., University of Hawaii, Honolulu, Hawaii, 16 pp. 